\title{
Anti-malarial activity and HS-SPME-GC-MS chemical profiling of Plinia cerrocampanensis leaf essential oil
}

\author{
Armando A Durant ${ }^{1,3^{*}+}$, Candelario Rodríguez ${ }^{1}$, Liuris Herrera ${ }^{2}$, Alejandro Almanza ${ }^{2}$, Ana I Santana ${ }^{3 \dagger}$, \\ Carmenza Spadadora ${ }^{2+}$ and Mahabir P Gupta ${ }^{4+}$
}

\begin{abstract}
Background: Plinia cerrocampanensis is an endemic plant of Panama. The leaf essential oil of this plant has shown antibacterial activity. However, anti-malarial activity and chemical profiling by HS-SPME-GC-MS of this essential oil have not been reported before.

Methods: Anti-malarial activity of the essential oil (EO) was evaluated in vitro against chloroquine-sensitive HB3 and chloroquine-resistant W2 strains of Plasmodium falciparum. Synergistic effect of chloroquine and the EO on parasite growth was evaluated by calculating the combination index. A methodology involving headspace solid phase microextraction and gas chromatography-mass spectrometry (HS-SPME-GC-MS) was developed to investigate the composition of Plinia cerrocampanensis EO.

Results: Plinia cerrocampanensis EO showed a high anti-malarial activity and a synergistic interaction with chloroquine. The Plinia cerrocampanensis EO inhibited $P$. falciparum growth in vitro at an $I_{50}$ of $7.3 \mu \mathrm{g} / \mathrm{mL}$. Chloroquine together with the $\mathrm{EO}$ decreased the $\mathrm{IC}_{50}$ of chloroquine from $0.1 \mu \mathrm{g} / \mathrm{mL}$ to $0.05 \mu \mathrm{g} / \mathrm{mL}$, and of the EO from $7.3 \mu \mathrm{g} / \mathrm{mL}$ to $1.1 \mu \mathrm{g} / \mathrm{mL}$. The measured combination index was 0.58 , which clearly indicates that the EO acts synergistically with chloroquine. Since the EO maintained its inhibitory activity on the chloroquine-sensitive strain of the parasite, it could be acting by a different mechanism of action than chloroquine. The best HS-SPME-GC-MS analytical conditions were obtained when the temperature of extraction was $49^{\circ} \mathrm{C}$, incubation time $14 \mathrm{~min}$, and the time of extraction $10 \mathrm{~min}$. This method allowed for the identification of 53 volatile constituents in the EO, including new compounds not reported earlier.
\end{abstract}

Conclusions: The anti-malarial activity exhibited by the Plinia cerrocampanensis EO may lend support for its possible use as an alternative for anti-malarial therapy.

Keywords: Malaria, Plinia cerrocampanensis, Plasmodium falciparum, Essential oil, Anti-malarial activity, Solid phase microextraction, Gas chromatography-mass spectrometry

\section{Background}

Malaria is a life-threatening tropical disease caused by five species of Plasmodium, the most deadly of them in humans being Plasmodium falciparum. According to the World Health Organization (WHO), malaria affected

\footnotetext{
* Correspondence: adurant@indicasat.org.pa

${ }^{\dagger}$ Equal contributors

${ }^{1}$ Center for Drug Discovery and Biodiversity, Institute of Scientific Research and Technology Services (INDICASAT), Panama, Panama

${ }^{3}$ Faculty of Natural, Exact Sciences and Technology, University of Panama, Panama, Panama

Full list of author information is available at the end of the article
}

219 million people around the world in 2010, causing over 600,000 deaths. On the other hand, increased rate of resistance to drugs used for treating patients has been observed over the past 20 years [1]. Chloroquine resistance has been reported in most of the malaria-endemic regions, while resistance to artemisinin has been detected in Cambodia, Thailand, Myanmar, and Vietnam [1]. These facts highlight the challenge in discovery of new drugs and new strategies for combating the disease. Historically natural products, such as aromatic plants, have been a source of new drugs and pharmacological

\section{Biomed Central}


alternatives for treating several diseases. The essential oils (EOs) are complex mixtures of terpenes and to a lesser extent of non-terpenoid compounds. Extensive research has been done on chemical characterization and determination of the antibacterial, antifungal, antileishmanial, and antiplasmodial activities of the EOs extracted from a wide variety of plants [2-7].

Plinia cerrocampanensis (Myrtaceae) is a tree that grows to a height of c. $8 \mathrm{~m}$ at an altitude of 800 and $1,000 \mathrm{~m}$ in the surroundings of Cerro Campana National Park (Panama) [8]. The EO of this plant has been reported to possess antimicrobial activity against Staphylococcus aureus, Pseudomonas aeruginosa, Microsporum gypseum, Trichophyton mentagrophytes, Trichophyton rubrum, and Helicobacter pylori [9]. However, its anti-malarial activity has not been reported before. Some terpenes have shown chemotherapeutic activity. For the extraction of the different terpenoids, and other compounds that constitute an EO, head-space solid phase microextraction (HSSPME) is a powerful tool that requires a minimal amount of sample. The isolated compounds are separated and identified by using GC-MS. SPME, which is a simple, fast, sensitive, solvent-free method developed by Pawliszyn et al. $[10,11]$ in the early 1990s, and used for research in many fields, such as cancer [12], medicinal plants [13] and metabolomic analysis [14]. This methodology was used by $\mathrm{Da}$ Porto and Decorti [15] for the determination of the aroma profile of the EO obtained by hydro-distillation of lavender (Lavandula angustifolia) flowers.

The present study aimed to (a) evaluate in vitro antimalarial activity of Plinia cerrocampanensis EO against P. falciparum; (b) study the possible synergistic inhibitory effect of chloroquine and the EO on the growth of the parasite; and (c) optimize a new HS-SPME-GC-MS methodology for identification of the volatile constituents of Plinia cerrocampanensis EO, which could possibly explain the observed anti-malarial activity.

\section{Methods}

\section{Plant material and extraction of the essential oil}

Fresh leaves of Plinia cerrocampanensis were collected in the Altos de Campana National Park (Province of Panama, Panama). The plant was identified by Alex Espinosa, taxonomist of CIFLORPAN, University of Panama. Leaves were protected from humidity and light until extraction of the EO. A voucher specimen No. 6623 is deposited in the Herbarium of the University of Panama (PMA). Plinia cerrocampanensis EO was extracted from $100 \mathrm{~g}$ of the collected plant material by hydrodistillation, for three hours, using a Clevenger-type apparatus as described in the European Pharmacopeia [16].

\section{Cytotoxicity assay}

Vero cells were seeded in 96-well plates using RPMI 1640 medium (Sigma-Aldrich, USA) supplemented with $10 \%$ foetal bovine serum (Gibco, Invitrogen, USA) and a combination of $1 \%$ penicillin/streptomycin. The cells were allowed to grow for 24 hours before adding the $\mathrm{EO}$, dissolved in dimethyl sulphoxide (DMSO), to final concentrations of $10,4,0.2$ and $0.08 \mu \mathrm{g} / \mathrm{mL}(\mathrm{w} / \mathrm{v})$. A negative control (with an equal volume of DMSO) was placed in all plates and counted as $100 \%$ growth. All samples were incubated for five days before staining and examining for reduction of 3-(4,5-dimethylthiazol-2-yl)2,5-diphenyltetrazolium bromide (MTT) (Sigma Aldrich, USA) and analysed four hours later in an ELISA plate reader at a wavelength of $570 \mathrm{~nm}$ [17].

\section{Anti-malarial activity}

The W2 and the HB3 strains of P. falciparum were obtained from the Malaria Research and Reference Reagent Resource Centre (MR4, Manassas, VA, USA), and maintained in continuous culture for about two months before new stocks were thawed. The parasites were grown and maintained in cultures using the method of Haynes et al. [18]. All chemicals except sodium bicarbonate and gentamicin (Gibco; Invitrogen, USA), were purchased from Sigma-Aldrich (USA). Cultures consisted of a $2 \%$ haematocrit suspension of $\mathrm{O}^{+}$human erythrocytes in RPMI 1640 medium supplemented with a gentamicin solution at $0.01 \mathrm{mg} / \mathrm{mL}, 25 \mathrm{mM}$ HEPES buffer, $25 \mathrm{mM} \mathrm{NaHCO}_{3}$, and $10 \%$ human serum. Cultures were fed with a gas mixture consisting of $5 \% \mathrm{CO}_{2}, 5 \% \mathrm{O}_{2}, 90 \% \mathrm{~N}_{2}$ and incubated in a cyclic incubator to achieve synchronization by temperatures, as described by Almanza et al. [19]. Estimation of the parasitaemia as well as visualization of parasite prior to the assays were done using normal light (Giemsa stain) microscopes. All samples were run in duplicate. The assay was carried out in 96-well plates at final concentrations of 10, 2, 0.4 and $0.08 \mu \mathrm{g} / \mathrm{mL}$ and re-evaluated at higher or lower concentrations as necessary. The final dilution contained less than $1 \%$ DMSO, which had no measurable effect on parasite survival. DMSO at a final concentration of $1 \%$ in RPMI 1640 culture media was used as a negative control. The positive control consisted of chloroquine (CQ) at concentrations of $1,000,200,100,50$, and $10 \mathrm{nM}$. The parasites were incubated for 48 hours at which point $50 \mu \mathrm{L}$ of a PicoGreen cocktail (Invitrogen, USA) were added to each well and the fluorescence determined after $30 \mathrm{~min}$ at $485 \mathrm{~nm}$ in a fluorometer. To measure the effect of the samples alone on the fluorescence signal, each extract concentration was incubated in the absence of parasites and the signal was subtracted from the value obtained in the presence of samples and parasites. For the synergistic studies, different doses of CQ (10, 50, 100, 200 and 1,000 nM) and Plinia cerrocampanensis EO (0.08, 0.4, 2 and $10 \mu \mathrm{g} / \mathrm{ml})$ were 
used, maintaining constant the concentration of one while varying the other.

Statistical analysis was carried out with the LSW DATb add-on of Microsoft Office Excel. The significance level was $\mathrm{p}<0.05$.

\section{Solid phase microextraction fibre selection}

Three fibres were evaluated in this research: carboxen-polydimethylsiloxane StableFlex (CAR/PDMS, $75 \mu \mathrm{m})$, polydimethylsiloxane-divinylbenzene StableFlex (PDMS/DVB, $65 \mu \mathrm{m}$ ), and divinylbenzenecarboxen-polydimethylsiloxane StableFlex (DVB/CAR/ PDMS 50/30 $\mu \mathrm{m}$ ) (Supelco, Bellefonte, PA, USA). All fibres were conditioned in the gas chromatograph injector port at the temperature and time recommended by the manufacturer.

Five hundred milligrams of Plinia cerrocampanensis EO (liquid matrix) were transferred to a $10 \mathrm{~mL}$ vial and hermetically sealed. The sample was equilibrated during $20 \mathrm{~min}$ at $30^{\circ} \mathrm{C}$ in a thermostatic bath. Then the fibre was exposed to sample headspace for $15 \mathrm{~min}$. After the sampling period, the SPME fibre was inserted into the GC injector port and maintained there for $7 \mathrm{~min}$ at $250^{\circ} \mathrm{C}$ for desorption of compounds.

\section{Experimental design}

The times of incubation and extraction and temperature of extraction are critical parameters that determine the equilibrium, vapour pressures and extraction efficiency of volatiles in the headspace [20]. These variables, which strongly influence the efficiency of the HS-SPME-GCMS, were optimized by using a Doehlert design. Sixteen randomized experiments were performed in duplicate. The total GC-MS peak areas were used as response. Statistical analysis was done using Statgraphics Plus 5.1 (Statistical Graphics, Rockville, MD, USA).

\section{Gas chromatography-mass spectrometry analysis}

All the analyses were performed on an Agilent $6890 \mathrm{~N}$ gas chromatograph (GC) equipped with a 5975C massselective detector (MSD) with triple-axis detector (Agilent Technologies, Palo Alto, CA, USA). The separation was achieved on a DB5-MS capillary column (30 m length, $0.25 \mathrm{~mm}$ id, $0.25 \mu \mathrm{m}$ film thickness), Agilent Technologies, Palo Alto, CA, USA).

Gas chromatograph oven initial temperature was kept at $50^{\circ} \mathrm{C}$ for $2 \mathrm{~min}$, then increased to $240^{\circ} \mathrm{C}$ at $6^{\circ} \mathrm{C} \mathrm{min}{ }^{-1}$ and held for $5 \mathrm{~min}$. The injector temperature was maintained at $250^{\circ} \mathrm{C}$, using splitless injection mode ( $\left.2 \mathrm{~min}\right)$. Helium was used as carrier gas with a constant flow-rate of $1 \mathrm{~mL} \mathrm{~min}^{-1}$. The mass spectrometer was operated in scan mode from $30-550 \mathrm{~m} / \mathrm{z}$; ion source temperature was set at $250^{\circ} \mathrm{C}$; the ionization was performed in the impact ionization mode (EI) with the ionization voltage set to $70 \mathrm{eV}$.
Identification of the compounds was carried out based on comparison of their fragmentation patterns using authentic standards when available and the NIST 11 Mass Spectral Search Program (NIST, Washington, USA), and with data from the literature [21]. Further identification of the compounds was achieved by comparison of their calculated experimental linear Kovat's retention indices (KI) with those reported in the literature using chromatographic columns of similar stationary phase composition.

\section{Results}

Headspace solid phase microextraction fibre selection

The first HS-SPME parameter optimized for characterization of the metabolites of Plinia cerrocampanensis EO was the selection of the SPME fibre. In this study three

Table 1 MS detector peak area of some volatile metabolites in Plinia cerrocampanensis essential oil analysed by using three different SPME fibres

\begin{tabular}{|c|c|c|c|c|}
\hline & & \multicolumn{3}{|c|}{ Mean MS response value $\left(\times 10^{7}\right)$} \\
\hline \multicolumn{2}{|c|}{ Compound } & DVB/CAR/PDMS & CAR/PDMS & DVB/PDMS \\
\hline 1 & Furfural & 67.2 & - & - \\
\hline 2 & a-Pinene & 584.0 & 632.0 & 894.0 \\
\hline 3 & Benzaldehyde & 257.0 & - & 201.0 \\
\hline 4 & y-Terpinene & 1150.0 & 799.5 & - \\
\hline 5 & Terpinolene & 547.0 & - & - \\
\hline 6 & Linalool & 2390.0 & - & 2630.0 \\
\hline 7 & Neo-allo-ocimene & 106.0 & 239.7 & 30.8 \\
\hline 8 & 4-Terpineol & 599.0 & 467.0 & 660.0 \\
\hline 9 & a-Terpineol & 231.0 & 194.0 & 261.0 \\
\hline 10 & Nerol & 12.9 & 8.8 & 15.5 \\
\hline 11 & Geraniol & 26.8 & 14.3 & 30.8 \\
\hline 12 & a-Copaene & 663.0 & 639.0 & 741.0 \\
\hline 13 & Sativene & 11.1 & - & - \\
\hline 14 & a-Cedrene & 140.0 & - & 229.0 \\
\hline 15 & Caryophyllene & 114.0 & 112.0 & 132.0 \\
\hline 16 & a-Bergamotene & 112.0 & 105.1 & 129.0 \\
\hline 17 & Epi- $\beta$-santalene & 33.0 & - & - \\
\hline 18 & a-Humelene & 46.1 & 46.7 & 55.5 \\
\hline 19 & $\beta$-Acoradiene & 69.2 & 81.3 & 93.2 \\
\hline 20 & Y-Muurolene & 89.6 & 87.2 & 103.0 \\
\hline 21 & a-Muurolene & 80.3 & 53.5 & 96.4 \\
\hline 22 & a-Curcumene & 191.0 & 170.9 & 184.0 \\
\hline 23 & $\beta$-Bisabolene & 907.0 & 480.3 & 1100.0 \\
\hline 24 & §-Cadinene & 291.0 & 277.0 & 328.0 \\
\hline 25 & trans-Nerolidol & 195.0 & 83.8 & 243.0 \\
\hline 26 & Cubenol & 11.8 & 8.4 & - \\
\hline 27 & Bisabolol oxide II & 37.9 & - & 47.7 \\
\hline 28 & a-Bisabolol & 159.0 & 58.0 & 213.0 \\
\hline
\end{tabular}


Table 2 Experimental Doehlert design matrix used for optimization of extraction parameters of Plinia cerrocampanensis essential oil by HS-SPME

\begin{tabular}{lllll}
\hline Experiment & Extraction temperature $\left({ }^{\circ} \mathbf{C}\right)$ & Time of equilibrium $(\mathbf{m i n})$ & Time of extraction $(\mathbf{m i n})$ & Total peak area $\left(\mathbf{1 0}^{\mathbf{9}}\right)$ \\
\hline 1 & & & & 136.86 \\
2 & 45 & 25 & 20 & 1.41 \\
3 & 60 & 25 & 20 & 6.84 \\
4 & 52 & 40 & 35 & 9.47 \\
5 & 52 & 25 & 25 & 50.99 \\
6 & 30 & 25 & 20 & 43.98 \\
7 & 38 & 10 & 5 & 111.39 \\
8 & 38 & 25 & 15 & 139.92 \\
9 & 52 & 10 & 5 & 137.97 \\
10 & 52 & 25 & 15 & 106.08 \\
11 & 38 & 10 & 35 & 100.77 \\
12 & 45 & 40 & 30 & 100.85 \\
13 & 38 & 40 & 25 & 122.17 \\
14 & 45 & 40 & 10 & 121.96 \\
15 & 45 & 40 & 10 & 122.20 \\
16 & 45 & 40 & 10 & 120.34 \\
\hline
\end{tabular}

commercially available SPME fibres, with two or three different coating polymers, were compared for assessing their concentration capacity. SPME fibres with more than one coating have shown to be the most effective when studying medicinal and aromatic plants [22].

The extraction efficiency of each fibre was determined on the basis of two main criteria, the total MS-detector peak area and the number of identified compounds. The DVB/ CAR/PDMS fiber permitted the identification of a larger number of constituents of the EO than CAR/PDMS and DVB/PDMS fibers. Furthermore, DVB/CAR/PDMS total peak response $\left(9.12 \times 10^{10}\right)$ was higher than that obtained with DVB/PDMS $\left(8.42 \times 10^{10}\right)$ and CAR/PDMS $(4.55 \times$ $10^{10}$ ) fibres (Table 1 ). DVB/CAR/PDMS is an adsorption- based fibre made of polydimethylsiloxane (PDMS) coating that allows the absorption of less polar substances; carboxen (CAR) and divinylbenzene (DVB) porous coating materials that provide high selectivity and sensitivity for more polar compounds. This fibre was selected as the most appropriate for obtaining the widest composition profile of Plinia cerrocampanensis EO, and was used in all further experiments.

\section{Optimization of the HS-SPME extraction procedure}

The times of extraction and incubation and temperature of extraction are important factors that determine the efficiency of the overall HS-SPME extraction process [23]. Thus, these parameters were optimized by using a three-

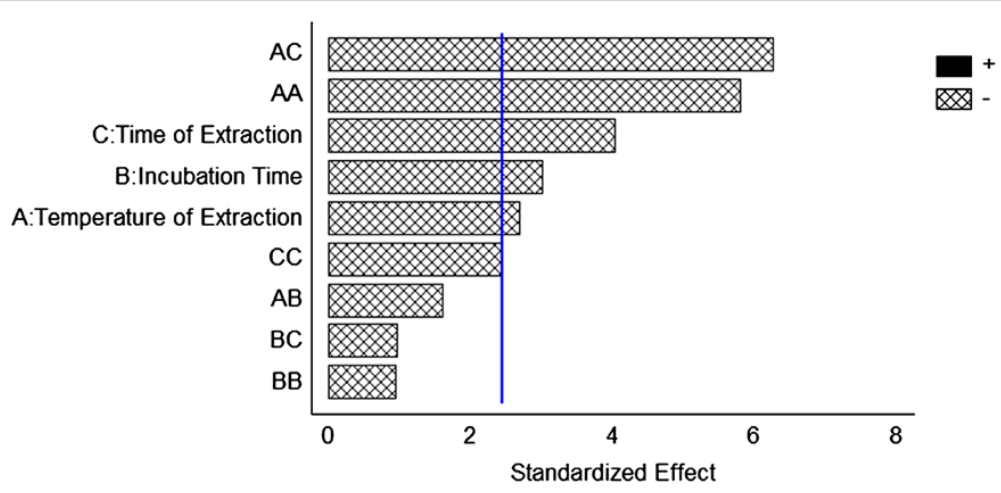

Figure 1 Pareto chart of standardized effects of extraction temperature, time of incubation and time of extraction. 
variable Doehlert design. This multivariate method allows for the simultaneous evaluation of the factors under study. Table 2 shows the experimental Doehlert design matrix and the response in terms of total area of the compounds identified from Plinia cerrocampanensis EO (liquid matrix). The design consisted of 16 randomized experiments to avoid systematic errors. Analysis of variance (ANOVA) was performed for determining the statistical significance $(\mathrm{p}<0.05)$.

Figure 1 shows the Pareto chart of the standardized effects. As can be observed, all three of the evaluated factors were significant, and increasing their value affected negatively the extraction. Among the HS-SPME parameters studied the time of extraction had the greatest influence on the extraction efficiency, while the temperature of extraction was less significant.

HS-SPME is an equilibrium process among three phases, the sample matrix, a gaseous headspace and the fibre coating. A first equilibrium is established between the analytes in the matrix and the headspace; subsequently, the SPME fibre is introduced in the headspace leading to a new equilibrium between the analytes in the headspace and in the fibre [24]. By raising the temperature the amount of analytes released from Plinia cerrocampanensis EO and extracted by the SPME fibre increased until an optimal value at $49^{\circ} \mathrm{C}$ (Figure 2A), after which higher temperatures influenced negatively the results. As the extraction temperature increases the Henry's constant of the analytes also increases, as well as the amount of compounds released from the liquid phase, especially less volatile compounds. Both physicochemical phenomena improve the extraction efficiency. Nevertheless, above $49^{\circ} \mathrm{C}$ the amount of compounds extracted by the $\mathrm{SPME}_{\mathrm{DVB} / \mathrm{CAR} / \mathrm{PDMS}}$ fibre tends to decrease due to desorption of compounds from the fibre.

Incubation time influences the number of compounds that are transferred from the liquid matrix and reach the headspace. The effect of this variable on analytical response is shown in Figure 2. A maximum response was observed at $14 \mathrm{~min}$. No improvement on extraction of EO metabolites was observed by increasing the incubation time.

In order to assess the effect of extraction time on the analysis, the $\mathrm{SPME}_{\mathrm{DVB} / \mathrm{CAR} / \mathrm{PDMS}}$ fibre was introduced into the sample headspace for different periods. The optimal response was achieved with an extraction time of $10 \mathrm{~min}$ (Figure 2). HS-SPME is an equilibrium process influenced strongly by the partition coefficient of the compounds between the liquid phase and the headspace $\left(\mathrm{K}_{\text {fiber/matrix }}\right)$.

Withdrawing the SPME fibre from the headspace before $10 \mathrm{~min}$ did not allow this equilibrium to be achieved, and hence less metabolites were extracted. Conversely, higher time of extraction reduced the total volatile recovery due to diffusion of the analytes from the fibre [25].
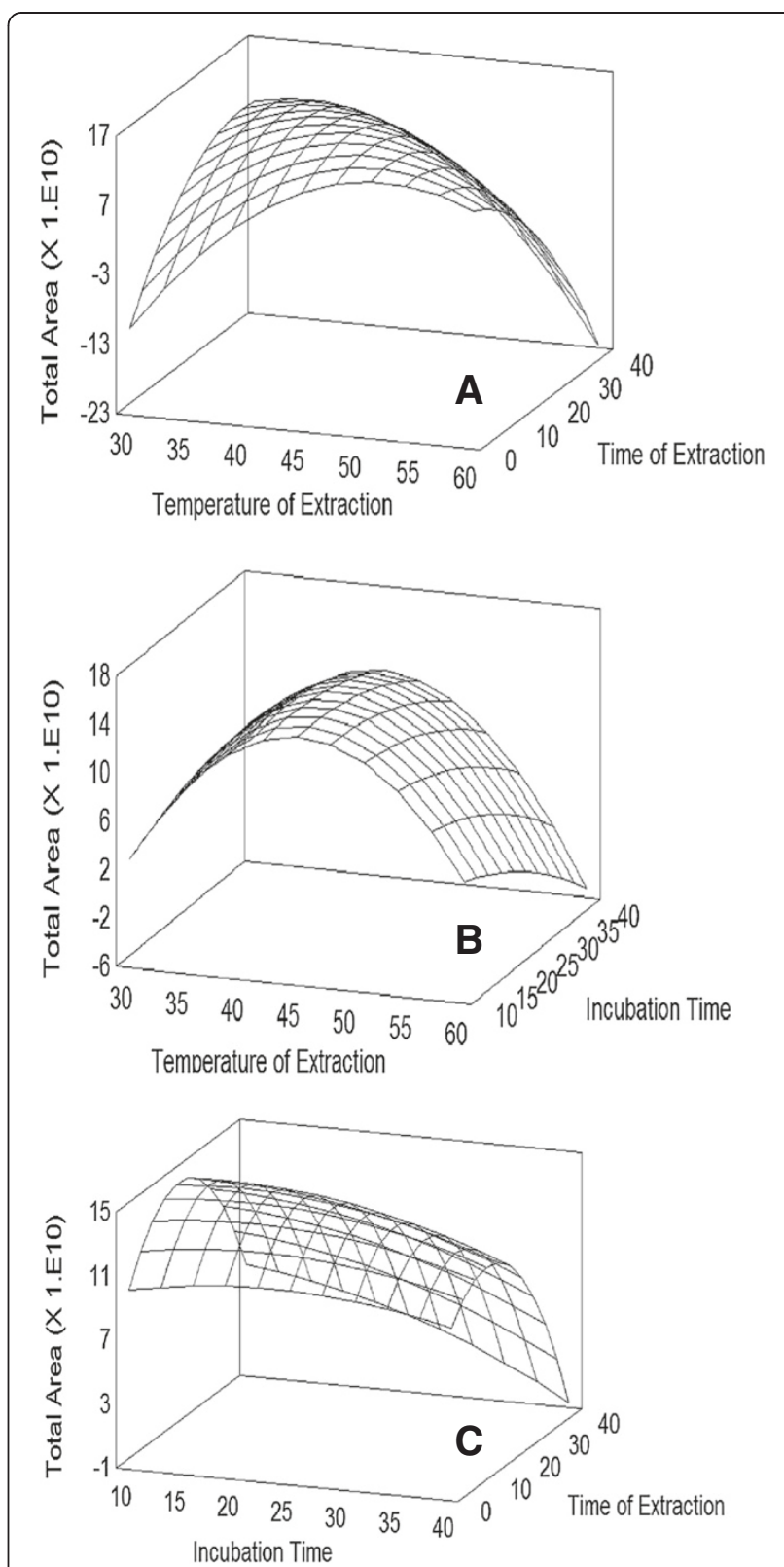

Figure 2 Fitted response surface plot. (A) Extraction temperature $\left({ }^{\circ} \mathrm{C}\right)$ vs time of extraction (min). (B) Extraction temperature $\left({ }^{\circ} \mathrm{C}\right)$ vs time of incubation (min). (C) Time of incubation (min) vs time of extraction (min).

According to the experimental results, the best analytical response was obtained when the temperature of extraction was $49^{\circ} \mathrm{C}$, incubation time $14 \mathrm{~min}$, and time of extraction $10 \mathrm{~min}$. These optimal values were selected for extraction of the EO metabolites in all further experiments.

\section{Chemical composition of the essential oil of Plinia cerrocampanensis by HS-SPME-GC-MS}

This is the first time that the chemical composition profiling of Plinia cerrocampanensis EO has been studied by 
Table 3 Chemical composition of Plinia cerrocampanensis B. essential oil by HS-SPME-GC-MS

\begin{tabular}{|c|c|c|c|c|}
\hline Peak no & Compound & $\mathrm{KI}^{\mathrm{a}}$ & $\mathrm{m} / \mathbf{z}$ & Percentage composition (\%) \\
\hline 1 & Furfural & 830 & $95-67-42$ & 0.21 \\
\hline 2 & a-Pinene & 933 & $93-79-41$ & 1.96 \\
\hline 3 & Benzaldehyde & 958 & $105-77-51$ & 1.10 \\
\hline 4 & Myrcene & 982 & $41-93-69$ & 0.91 \\
\hline 5 & 3- $\delta$-Carene & 1006 & $93-79-41$ & 0.90 \\
\hline 6 & o-Cymene & 1020 & $119-91-134$ & 6.85 \\
\hline 7 & trans- $\beta$-Ocimene & 1041 & $93-79-41$ & 2.62 \\
\hline 8 & cis- $\beta$-Ocimene & 1053 & $93-91-79$ & 2.58 \\
\hline 9 & $\gamma_{\text {-Terpinene }}$ & 1067 & $93-77-41$ & 4.70 \\
\hline 10 & Terpinolene & 1092 & $93-121-136$ & 2.01 \\
\hline 11 & Linalool & 1104 & $43-71-55$ & 10.47 \\
\hline 12 & Fenchol & 1121 & $81-43-67$ & 0.06 \\
\hline 13 & cis-Sabinol & 1133 & $92-81-109$ & 0.11 \\
\hline 14 & Neo-allo-ocimene & 1140 & $121-105-79$ & 2.72 \\
\hline 15 & 1,4-Dimethyl-4-acetyl-1-cyclohexene & 1157 & $109-67-43$ & 0.04 \\
\hline 16 & Trans,cis-2,6-Nonadienal & 1163 & $41-70-39$ & 0.05 \\
\hline 17 & Terpin-4-en-1-ol & 1174 & $43-71-93$ & 2.22 \\
\hline 18 & m-Methylacetophenone & 1188 & $119-91-65$ & 0.15 \\
\hline 19 & a-Terpinol & 1196 & $59-43-93$ & 1.20 \\
\hline 20 & $\beta$-Cyclocitral & 1214 & $41-137-123$ & 0.06 \\
\hline 21 & Nerol & 1229 & $41-69-81$ & 0.12 \\
\hline 22 & p-Menth-1(7)-en-2-one & 1241 & $82-81-152$ & 0.07 \\
\hline 23 & Carvenone & 1248 & $95-110-67$ & 0.18 \\
\hline 24 & Geraniol & 1255 & $41-69-81$ & 0.29 \\
\hline 25 & cis-2-Decenal & 1272 & $41-55-70$ & 0.04 \\
\hline 26 & Carvacrol & 1313 & $135-91-150$ & 0.05 \\
\hline 27 & a-Copaene & 1365 & 105-119-161 & 8.86 \\
\hline 28 & Sativene & 1390 & $108-41-91$ & 0.19 \\
\hline 29 & Ylangene & 1400 & 105-119-93 & 0.89 \\
\hline 30 & a-Cedrene & 1412 & $119-41-105$ & 0.92 \\
\hline 31 & trans- $\beta$-Caryophyllene & 1420 & $41-91-79$ & 1.34 \\
\hline 32 & a-Bergamotene & 1440 & $41-93-119$ & 1.93 \\
\hline 33 & $\gamma$-Elemene & 1449 & $121-41-93$ & 1.24 \\
\hline 34 & Epi- $\beta$-santalene & 1453 & $94-41-79$ & 0.52 \\
\hline 35 & a-Humelene & 1458 & $93-41-67$ & 0.54 \\
\hline 36 & $\beta$-Farnesene & 1462 & $41-69-91$ & 1.97 \\
\hline 37 & $\beta$-Acoradiene & 1469 & $119-41-105$ & 1.05 \\
\hline 38 & $\gamma$-Gurjunene & 1476 & $105-91-81$ & 0.82 \\
\hline 39 & $\gamma$-Muurolene & 1484 & $161-41-105$ & 1.42 \\
\hline 40 & a-Curcumene & 1490 & $119-132-41$ & 3.83 \\
\hline 41 & Indipone & 1499 & $149-93-41$ & 1.18 \\
\hline 42 & a-Muurolene & 1507 & $105-41-161$ & 0.95 \\
\hline 43 & $\beta$-Bisabolene & 1513 & $41-69-93$ & 16.26 \\
\hline 44 & -Cadinene & 1527 & $119-161-41$ & 4.21 \\
\hline
\end{tabular}


Table 3 Chemical composition of Plinia cerrocampanensis B. essential oil by HS-SPME-GC-MS (Continued)

\begin{tabular}{|c|c|c|c|c|}
\hline 45 & $\gamma$-Bisabolene & 1540 & 41-93-107 & 2.19 \\
\hline 46 & trans- Nerolidol & 1558 & 41-69-93 & 2.68 \\
\hline 47 & Spathulenol & 1569 & 43-91-79 & 0.27 \\
\hline 48 & tau-Cadinol & 1632 & $43-161-81$ & 0.26 \\
\hline 49 & Cubenol & 1649 & $43-161-95$ & 0.26 \\
\hline 50 & Bisabolol oxide B & 1666 & 43-59-105 & 0.92 \\
\hline 51 & $\beta$-Bisabolol & 1674 & $41-67-93$ & 0.15 \\
\hline 52 & a-Bisabolol & 1687 & 43-119-109 & 3.46 \\
\hline 53 & a-Farnesol & 1709 & $41-69-81$ & 0.01 \\
\hline
\end{tabular}

Retention index. Components are listed in increasing order of their retention indices on DB5-MS.

using HS-SPME-GC-MS approach. Table 3 lists the constituents identified in the EO analysed. Fifty-three compounds were identified by this methodology. The main constituents (more than 2\% of the identified compounds) were $\beta$-bisabolene, $\beta$-linalool, $\alpha$-copaene, $o$-cymene, $\gamma$ - terpinene, $\delta$-cadinene, $\alpha$-curcumene, $\alpha$ bisabolol, neo-allo-ocimene, trans-nerolidol, trans- $\beta$-ocimene, $\beta$-ocimene, $\gamma$-bisabolene and terpinolene (Table 3 ). Vila et al. have reported the chemical composition of the EO obtained from leaves of Plinia cerrocampanensis utilizing two different GC-columns, i e, a non-polar and a polar phase columns, identifying 40 compounds: 33 compounds were identified on the non-polar phase column, and 31 on the polar phase column [9]. Clearly, the more sensitive HS-SPME-GC-MS methodology developed in this study allowed the identification of a higher number of compounds in a single chromatographic run.

The current investigation reports for the first time new compounds present in the EO obtained from leaves of Plinia cerrocampanensis, such as neo-alloocimene, $\gamma$-elemene, caryophyllene, acoradiene, $\gamma$ muurolene, and $\beta$-myrcene.

Sesquiterpene hydrocarbons (49.13\%), and monoterpene hydrocarbons (25.25\%) were the most abundant chemical class of compounds identified by HS-SPMEGC-MS, followed by oxygenated monoterpenes (15.03\%), oxygenated sesquiterpenes $(9.19 \%)$ and aldehydes (1.35\%).

\section{Anti-malarial activity}

This is the first report on the anti-malarial activity of the EO from Plinia cerrocampanensis. The antiplasmodial effects of Plinia cerrocampanensis EO were determined by quantifying the growth inhibition of the CQ-resistant $P$. falciparum W2 strain when compared with parasites cultured in a medium free of the EO. The Plinia cerrocampanensis $\mathrm{EO}$ inhibited parasite growth in vitro at $\mathrm{IC}_{50} 7.3 \mu \mathrm{g} / \mathrm{mL}$. This value indicates a high antiplasmodial activity. The activity of the oil was lower than that of chloroquine $\left(\mathrm{IC}_{50}=0.1 \mu \mathrm{g} / \mathrm{mL}\right)$, which could result from several factors, one of them being the dilution of the active compound (s) in the matrix.

To get an idea of the mechanism by which the EO was acting on $P$. falciparum, its activity against a CQ-sensitive strain, HB3, was tested and compared the results with those obtained with the CQ-resistant W2. While CQ shows difference in $\mathrm{IC}_{50}$ in the resistant $\left(\mathrm{IC}_{50}=0.1 \mu \mathrm{g} / \mathrm{mL}\right)$ and sensitive $\left(\mathrm{IC}_{50}=0.01 \mu \mathrm{g} / \mathrm{mL}\right)$ strains, the $\mathrm{EO}$ maintained its level of activity, in both the resistant $\left(\mathrm{IC}_{50}=7.3 \mu \mathrm{g} / \mathrm{mL}\right)$ and sensitive $\left(\mathrm{IC}_{50}=10.2 \mu \mathrm{g} / \mathrm{mL}\right)$ strains. These results suggest that the EO may be using another mechanism that does not involve inhibition of $\beta$-haematin formation nor inhibition of the peroxidative degradation of haemin, since $C Q$ and other quinolones with anti-malarial activity are thought to act through these two mechanisms [26,27].

The EO caused toxicity to mammalian cells at a concentration of $28.6 \mu \mathrm{g} / \mathrm{mL}$, which is four-fold higher than the concentration at which the oil showed antiplasmodial effects, projecting a reasonable therapeutic window for its use in vivo. The HS-SPME-GC-MS methodology developed in this study allowed the identification of terpenes and terpenoids in the EO of Plinia cerrocampanensis: $\alpha$-pinene, $\beta$-linalool, trans-nerolidol, $\alpha$-bisabolol and $\alpha$-farnesol, which have been reported to possess antiplasmodial activity and, therefore, may explain the observed anti-malarial activity of EO [28-30].

The monoterpene $\alpha$-pinene displayed a stronger antimalarial activity than quinine when tested against a CQresistant strain of $P$. falciparum, mainly affecting the ring stage of the parasite [29]. $\beta$-linalool and farnesol arrest the growth of the apicomplexan mainly by (a) affecting the dolichol biosynthesis at the trophozoite and schizont stages; and, (b) inhibiting the biosynthesis of the isoprene side chain of the benzoquinone ring of ubiquinones [30]. Treatment of P. falciparum with the isolated oxygenated sesquiterpene $\alpha$-bisabolol caused inhibition in the development of parasites [30]. Macedo et al. demonstrated the high activity of the sesquiterpene trans-nerolidol against $P$. falciparum by decreasing its ability to biosynthesize the isoprene chain attached to 


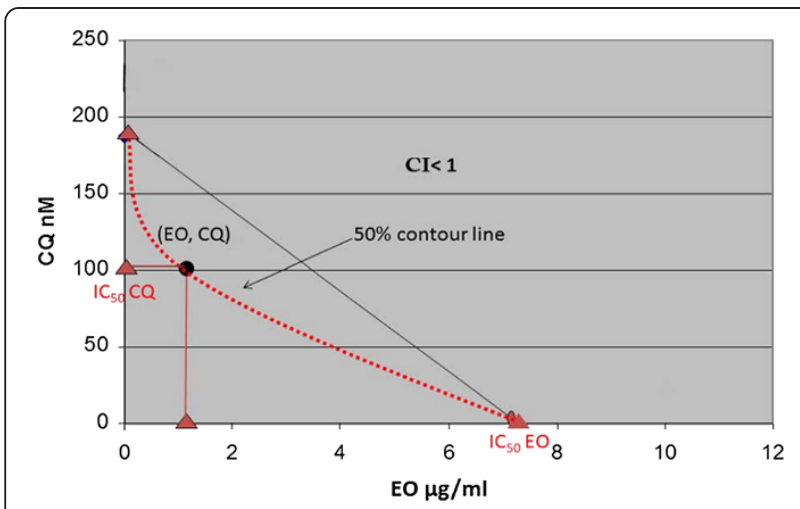

Figure 3 Isobologram and combination index $(\mathrm{Cl})$ of chloroquine (CQ) and the essential oil (EO) of Plinia cerrocampanensis. The $50 \%$ contour line shows a less than 1 combination index which shows synergy between EO and CQ at concentration (EO, CQ).

coenzyme Q [31]. In most cases, the anti-malarial activity displayed by the Plinia cerrocampanensis EO was higher than the activity observed for these compounds, suggesting that trace components of the oil could be enhancing the effect of the active components. A possible synergism among the different constituents of the oil could also be responsible for its anti-malarial activity.

To determine possible synergistic or additive effects when applied with other drugs, the activity of the EO was examined in conjunction with $C Q$ at different concentrations. Synergism or additive effect was evaluated by calculating the combination index $(\mathrm{CI})$ as described by Chou and Talahay [32] using the following formula:

$$
\mathrm{CI}=\frac{(\mathrm{D})_{1}}{\left(\mathrm{D}_{\mathrm{x}}\right)_{1}}+\frac{(\mathrm{D})_{2}}{\left(\mathrm{D}_{\mathrm{x}}\right)_{2}}=\frac{1}{(\mathrm{DRI})_{1}}+\frac{1}{(\mathrm{DRI})_{2}}
$$

where $\mathrm{D}$ is the concentration at which both compounds show the same desired efficacy (ED) in combination, and $D_{x}$ is the concentration at which each of the compounds alone show this ED [32]. A synergistic effect is achieved if $\mathrm{CI}$ is $<1.0$ while an additive effect is obtained at $\mathrm{CI}=1.0$. The application of CQ together with the $\mathrm{EO}$ on strains of $P$. falciparum, decreased the $\mathrm{IC}_{50}$ for $\mathrm{CQ}$ from $0.1 \mu \mathrm{g} / \mathrm{mL}$ to $0.05 \mu \mathrm{g} / \mathrm{mL}$, and for the EO from $7.3 \mu \mathrm{g} / \mathrm{mL}$ to $1.1 \mu \mathrm{g} / \mathrm{mL}$ (Figure 3).

This means that a higher in vitro activity against the parasite was obtained for the oil and CQ when applied together. The measured CI combination was 0.58 , which clearly indicates that the EO acted synergistically with $\mathrm{CQ}$. Moreover, the therapeutic window of the EO increased substantially in the presence of a very small amount of CQ. Based on the physico-chemical properties of the EO, it could also cause the disruption of the parasite cell membrane, which affects the permeability of the cell and the transfer of important biochemical substances needed by the parasite for sustaining crucial metabolic processes. The reduction in the concentration of CQ required for achieving its therapeutical effect may not only lower the incidence of adverse reactions in humans, but most importantly, may promote the use of this cost effective drug in the large regions worldwide where resistance to it has been observed.

\section{Conclusions}

This research demonstrated that the EO of Plinia cerrocampanensis could be a potential alternative for the treatment of malaria. Moreover, due to the synergistic anti-malarial activity of the $\mathrm{EO}$ and the $\mathrm{CQ}$, this could be used in combination with CQ as anti-malarial therapy. The studies are underway to determine the anti-malarial effect of major isolated compounds in the EO of Plinia cerrocampanensis.

The developed HS-SPME-GC-MS methodology allowed for the identification of new constituents in the EO of Plinia cerrocampanensis. Monoterpenes and sesquiterpenes, which constitute most of the volatile organic compounds of the essential oil, could be responsible for the bioactivity showed by the oil in this study.

\section{Abbreviations}

EO: Essential oil; HS-SPME: Headspace-solid phase microextraction; GC: Gas chromatography; MS: Mass spectrometry.

\section{Competing interests}

The authors declare that they have no competing interests.

\section{Authors' contributions}

CS, MPG and AAD participated in research design and critical review of the manuscript; MPG supplied plant material and suggested this research; AIS, $\mathrm{CR}, \mathrm{LH}, \mathrm{AA}$ and $\mathrm{AAD}$ conducted experiments; AIS, CS and AAD performed data analysis; CS and MPG contributed in the writing and revision of the manuscript; AAD drafted and wrote the final manuscript. All authors approved the final manuscript.

\section{Acknowledgements}

AD, CS and MPG would like to acknowledge SENACYT, Panama for supporting the National System of Investigators (SNI) and the Organization of American States for support to CIFLORPAN.

\section{Author details}

${ }^{1}$ Center for Drug Discovery and Biodiversity, Institute of Scientific Research and Technology Services (INDICASAT), Panama, Panama. ${ }^{2}$ Center for Cellular and Molecular Biology of Diseases, Institute of Scientific Research and Technology Services (INDICASAT), Panama, Panama. ${ }^{3}$ Faculty of Natural, Exact Sciences and Technology, University of Panama, Panama, Panama. ${ }^{4}$ Center of Pharmacognostic Research on Panamanian Flora (CIFLORPAN), College of Pharmacy, University of Panama, P.O. Box 0824-00172, Panama, Panama.

Received: 15 August 2013 Accepted: 9 January 2014

Published: 13 January 2014

\section{References}

1. World Health Organization: World Malaria Report 2012. Geneva: WHO Press; 2012.

2. Oji KA, Shafaghat A: Constituents and antimicrobial activity of the essential oils from flower, leaf and stem of Helichrysum armenium. Nat Prod Commun 2012, 7:671-674. 
3. Marwah RG, Fatope MO, Deadman ML, Ochei JE, Al-Saidi SH: Antimicrobial activity and the major components of the essential oil of Plectranthus cylindraceus. J Appl Microbiol 2007, 103:1220-1226.

4. Waikedre J, Vitturo $\mathrm{Cl}$, Molina A, Theodoro PN, do Rosário Rodrigues Silva M, Espindola LS, Maciuk A, Fournet A, Theodoro PN: Antifungal activity of the essential oils of Callitris neocaledonica and C. sulcata Heartwood (Cupressaceae). Chem Biodivers 2012, 9:644-653.

5. Ahmed SB, Sghaier RM, Guesmi F, Kaabi B, Mejri M, Attia H, Laouini D, Smaali I: Evaluation of antileishmanial, cytotoxic and antioxidant activities of essential oils extracted from plants issued from the leishmaniasis-endemic region of Sned (Tunisia). Nat Prod Res 2011, 25:1195-1201.

6. Dell'agli M, Sanna C, Rubiolo P, Basilico N, Colombo E, Scaltrito MM, Ndiath MO, Maccarone L, Taramelli D, Bicchi C, Ballero M, Bosisio E: Antiplasmodial and insecticidal activities of the essential oils of aromatic plants growing in the Mediterranean area. Malar J 2012, 11:219.

7. Boyom FF, Ngouana V, Zollo PH, Menut C, Bessiere JM, Gut J, Rosenthal PJ: Composition and anti-plasmodial activities of essential oils from some Cameroonian medicinal plants. Phytochemistry 2003, 64:1269-1275.

8. Barrie FR: Synopsis of Plinia (Myrtaceae) in Mesoamerica. Novon 2004, 14:380-400.

9. Vila R, Santana Al, Pérez-Rosés R, Valderrama A, Castelli MV, Mendonca S, Zacchino S, Gupta MP, Cañigueral S: Composition and biological activity of the essential oil from leaves of Plinia cerrocampanensis, a new source of -a-bisabolol. Bioresour Technol 2010, 101:2510-2514.

10. Arthur C, Pawliszyn J: Solid phase microextraction with thermal desorption using fused silica optical fibers. Anal Chem 1990 62:2145-2148

11. Zhang Z, Pawliszyn J: Headspace solid-phase microextraction. Anal Chem 1993, 65:1843-1852.

12. Monteleone M, Naccarato A, Sindona G, Tagarelli A: A reliable and simple method for the assay of neuroendocrine tumor markers in human urine by solid-phase microextraction-gas chromatography-triple quadrupole mass spectrometry. Anal Chim Acta 2013, 759C:66-73.

13. Belliardo F, Bicchi C, Cordero C, Liberto E, Rubiolo P, Sgorbini B: Headspacesolid-phase microextraction in the analysis of the volatile fraction of aromatic and medicinal plants. Chromatogr Sci 2006, 44:416-429.

14. Dixon E, Clubb C, Pittman S, Ammann L, Rasheed Z, Kazmi N, Keshavarzian A, Gillevet P, Rangwala H, Couch RD: Solid-phase microextraction and the human fecal VOC metabolome. PLoS One 2011, 8:e18471.

15. Da Porto C, Decorti D: Analysis of the volatile compounds of flowers and essential oils from Lavandula angustifolia cultivated in Northeastern Italy by headspace solid-phase microextraction coupled to gas chromatography-mass spectrometry. Planta Med 2008, 74:182-177.

16. Council of Europe: European Pharmacopeia, vol. 1. Strasbourg: European Council; 2005.

17. Mosman T: Rapid colorimetric assay for cellular growth and survival: application to proliferation and cytotoxicity assays. $J$ Immunol Methods 1983, 65:55-63.

18. Haynes JD, Diggs CL, Hines FA, Desjardins RE: Culture of human malaria parasites plasmodium falciparum. Nature 1976, 263:767-769.

19. Almanza A, Herrera L, Tayler N, Coronado L, Spadafora C: Automated synchronization of $P$. falciparum using a temperature cycling incubator. Curr Trends Biotechnol Pharm 2011, 5:1130-1133.

20. Durant A, Rodríguez C, Santana A, Herrero C, Rodríguez JC, Gupta MP: Analysis of volatile compounds from solanum betaceum Cav. Fruits from panama by head-space micro extraction. Rec Nat Prod 2013, 7:15-26.

21. Adams R: Identification of Essential Oil Components by gas chromatographymass spectrometry. Carol Stream: Allured Pub Corp; 2007.

22. Bicchi C, Drigo S, Rubiolo P: Influence of fiber coating in headspace solid-phase microextraction-gas chromatographic analysis of aromatic and medicinal plants. J Chromatogr A 2000, 892:469-485.

23. Pellati F, Benvenuti S, Yoshizaki F, Bertelli D, Rossi MC: Headspace solidphase microextraction-gas chromatography-mass spectrometry analysis of the volatile compounds of Evodia species fruits. J Chromatogr A 2005, 1087:265-273.

24. Pawliszyn J: Solid Phase Microextraction. Theory and Practice. New York: Wiley; 1997.

25. Achouri A, Boye Jl, Zamani Y: Identification of volatile compounds in soymilk using solid-phase microextraction-gas chromatography. Food Chem 2006, 99:759-766.
26. Ginsburg H, Ward SA, Bray PG: An integrated model of chloroquine action. Parasitol Today 1999, 15:357-360.

27. Loria P, Miller S, Foley M, Tilley L: Inhibition of the peroxidative degradation of haem as the basis of action of chloroquine and other antimalarials. Biochem J 1999, 339:363-370.

28. Lopes NP, Kato MJ, Andrade EH, Maia JG, Yoshida M, Planchart AR, Katzin AM: Antimalarial use of volatile oil from leaves of virola surinamensis (Rol.) warb. By waiãpi Amazon Indians. J Ethnopharmacol 1999, 67:313-319

29. van Zyl RL, Seatlholo ST, van Vuuren SF: The biological activities of 20 nature identical essential oil constituents. J Essent Oil Res 2006, 18:129-133.

30. Mota ML, Lobo LT, Costa JM, Costa LS, Rocha HA, Rocha e Silva LF, Pohlit $A M$, Neto VF: In vitro and in vivo antimalarial activity of essential oils and chemical components from three medicinal plants found in northeastern Brazil. Planta Med 2012, 78:658-64.

31. Macedo C, Uhrig M, Kimura E, Katzin A: Characterisation of the isoprenoid chain of coenzyme Q in Plasmodium falciparum. FEMS Microbiol Lett 2002, 207:13-20.

32. Chou T, Talalay P: Quantitative analysis of dose-effect relationships: the combined effects of multiple drugs or enzyme inhibitors. Adv Enzyme Regul 1984, 22:27-55.

doi:10.1186/1475-2875-13-18

Cite this article as: Durant et al:: Anti-malarial activity and HS-SPME-GC-

MS chemical profiling of Plinia cerrocampanensis leaf essential oil.

Malaria Journal 2014 13:18.

\section{Submit your next manuscript to BioMed Central and take full advantage of:}

- Convenient online submission

- Thorough peer review

- No space constraints or color figure charges

- Immediate publication on acceptance

- Inclusion in PubMed, CAS, Scopus and Google Scholar

- Research which is freely available for redistribution

Submit your manuscript at www.biomedcentral.com/submit
C BioMed Central 